\title{
Richard Hobbs and Bruce Arroll (eds): Cardiovascular risk management
}

\author{
Wiley-Blackwell, Oxford 2009, ISBN: 978-1-4051-5575-5
}

\author{
Paola Nargi • Luigi Mansi
}

Published online: 14 April 2010

(C) Springer-Verlag 2010

An updated text, which has the merit of taking stock of the situation in a field, the management of cardiovascular risk, where the fast and sudden classification of the patient is essential. This book is designed with a main interest in providing advice to general practitioners, young doctors, medical students and nurses on how to recognize and outline, reduce and treat pharmacologically major cardiovascular risk factors. But it can also be of interest in the area of nuclear medicine, as a didactic support to help both the choice of the diagnostic test and to better interpret diagnostic and prognostic data. The text, 90 pages for 12 chapters, can be schematically divided into three sections. The first deals with the epidemi- ology of cardiovascular disease and the guidelines used in different countries. The second section identifies the main risk factors that allow the subsequent classification of individual patients. The third one deals with care of patients at risk, giving valuable suggestions on proper lifestyle and taking any medication. Each chapter is accompanied by a valuable bibliography, which allows those who wish to deepen their knowledge of the subject matter with the appropriate documentation. In conclusion, the work is properly addressed to all those who wish to have an overview of the management of patients at risk for cardiovascular disease, including nuclear physicians involved in nuclear cardiology.

P. Nargi $(\bowtie) \cdot$ L. Mansi

Medicine Nuclear Unit, Second University of Naples,

Naples, Italy

e-mail: paolanargi@hotmail.com

L. Mansi

e-mail: Luigi.mansi@unina2.it 